NASA/TM-2013-217890

\title{
Further Development of Rotating Rake Mode Measurement Data Analysis
}

Milo D. Dahl

Glenn Research Center, Cleveland, Ohio

Ray Hixon

University of Toledo, Toledo, Ohio

Daniel L. Sutliff

Glenn Research Center, Cleveland, Ohio 


\section{NASA STI Program . . . in Profile}

Since its founding, NASA has been dedicated to the advancement of aeronautics and space science. The NASA Scientific and Technical Information (STI) program plays a key part in helping NASA maintain this important role.

The NASA STI Program operates under the auspices of the Agency Chief Information Officer. It collects, organizes, provides for archiving, and disseminates NASA's STI. The NASA STI program provides access to the NASA Aeronautics and Space Database and its public interface, the NASA Technical Reports Server, thus providing one of the largest collections of aeronautical and space science STI in the world. Results are published in both non-NASA channels and by NASA in the NASA STI Report Series, which includes the following report types:

- TECHNICAL PUBLICATION. Reports of completed research or a major significant phase of research that present the results of NASA programs and include extensive data or theoretical analysis. Includes compilations of significant scientific and technical data and information deemed to be of continuing reference value. NASA counterpart of peer-reviewed formal professional papers but has less stringent limitations on manuscript length and extent of graphic presentations.

- TECHNICAL MEMORANDUM. Scientific and technical findings that are preliminary or of specialized interest, e.g., quick release reports, working papers, and bibliographies that contain minimal annotation. Does not contain extensive analysis.

- CONTRACTOR REPORT. Scientific and technical findings by NASA-sponsored contractors and grantees.
- CONFERENCE PUBLICATION. Collected papers from scientific and technical conferences, symposia, seminars, or other meetings sponsored or cosponsored by NASA.

- SPECIAL PUBLICATION. Scientific, technical, or historical information from NASA programs, projects, and missions, often concerned with subjects having substantial public interest.

- TECHNICAL TRANSLATION. Englishlanguage translations of foreign scientific and technical material pertinent to NASA's mission.

Specialized services also include creating custom thesauri, building customized databases, organizing and publishing research results.

For more information about the NASA STI program, see the following:

- Access the NASA STI program home page at http://www.sti.nasa.gov

- E-mail your question to help@sti.nasa.gov

- Fax your question to the NASA STI Information Desk at 443-757-5803

- Phone the NASA STI Information Desk at 443-757-5802

- Write to: STI Information Desk NASA Center for AeroSpace Information 7115 Standard Drive Hanover, MD 21076-1320 
NASA/TM-2013-217890

\section{Further Development of Rotating Rake Mode Measurement Data Analysis}

Milo D. Dahl

Glenn Research Center, Cleveland, Ohio

Ray Hixon

University of Toledo, Toledo, Ohio

Daniel L. Sutliff

Glenn Research Center, Cleveland, Ohio

Prepared for the

19th Aeroacoustics Conference

cosponsored by the American Institute of Aeronautics and Astronautics and

Confederation of European Aerospace Societies

Berlin, Germany, May 27-29, 2013

National Aeronautics and

Space Administration

Glenn Research Center

Cleveland, Ohio 44135 


\section{Acknowledgments}

The NASA Fixed Wing Project of the Fundamental Aeronautics Program supported this work.

This report contains preliminary findings, subject to revision as analysis proceeds.

Trade names and trademarks are used in this report for identification only. Their usage does not constitute an official endorsement, either expressed or implied, by the National Aeronautics and Space Administration.

Level of Review: This material has been technically reviewed by technical management.

Available from

NASA Center for Aerospace Information 7115 Standard Drive

Hanover, MD 21076-1320
National Technical Information Service 5301 Shawnee Road Alexandria, VA 22312

Available electronically at http://www.sti.nasa.gov 


\title{
Further Development of Rotating Rake Mode Measurement Data Analysis
}

\author{
Milo D. Dahl \\ National Aeronautics and Space Administration \\ Glenn Research Center \\ Cleveland, Ohio 44135 \\ Ray Hixon \\ University of Toledo \\ Toledo, Ohio 43606 \\ Daniel L. Sutliff \\ National Aeronautics and Space Administration \\ Glenn Research Center \\ Cleveland, Ohio 44135
}

\begin{abstract}
The Rotating Rake mode measurement system was designed to measure acoustic duct modes generated by a fan stage. After analysis of the measured data, the mode amplitudes and phases were quantified. For low-speed fans within axisymmetric ducts, mode power levels computed from rotating rake measured data would agree with the far-field power levels on a tone by tone basis. However, this agreement required that the sound from the noise sources within the duct propagated outward from the duct exit without reflection at the exit and previous studies suggested conditions could exist where significant reflections could occur. To directly measure the modes propagating in both directions within a duct, a second rake was mounted to the rotating system with an offset in both the axial and the azimuthal directions. The rotating rake data analysis technique was extended to include the data measured by the second rake. The analysis resulted in a set of circumferential mode levels at each of the two rake microphone locations. Radial basis functions were then least-squares fit to this data to obtain the radial mode amplitudes for the modes propagating in both directions within the duct. The fit equations were also modified to allow evanescent mode amplitudes to be computed. This extension of the rotating rake data analysis technique was tested using simulated data, numerical code produced data, and preliminary in-duct measured data.
\end{abstract}

\section{Introduction}

A microphone rake system mounted in a fan duct and rotating at a fraction of the fan shaft speed can be used to measure the interaction modes of the ducted fan and stator system. By continuously rotating the microphone system in a manner locked to the fan shaft but at a slower speed, a Doppler shift is imparted to the measurement of the duct modes making individual co-rotating and counter-rotating modes easily identifiable. ${ }^{1}$ The success of the technique depends on the data analysis or post-processing of the measured signals from the microphones. The coefficients computed from the Fourier transform of the microphone signals represent the complex amplitudes of the spinning circumferential modes of the measured acoustic pressure field in the duct. These circumferential modes are further decomposed into a finite set of radial basis functions representing the radial modal structure of the acoustic field. The amplitudes of the radial basis functions are determined by a least-squares fit of the functions to the complex circumferential mode amplitudes at the radial microphone locations. Hall et al. ${ }^{2}$ developed the original data analysis technique for which the radial basis functions were the closed-form solutions to the equation for sound propagating in a hard-wall, circular duct with no mean flow (i.e., the Bessel functions). This type of analysis was subsequently extended by Sutliff ${ }^{3-5}$ to include the effects of a constant mean flow in a soft-wall duct. The closed-form 
solutions were still applied and the duct cross-section could be circular or annular. For the general case where a boundary layer exists at the wall of the duct, the data analysis using closed-form solutions may not be sufficiently accurate. Dahl \& Sutliff ${ }^{6}$ presented a numerical technique for computing the radial basis functions that are necessary for the proper analysis of the data from rotating rake mode measurements in a duct with flow. For a duct with acoustic treatment on the wall, the changes in the radial basis functions between the case with no flow in the duct and the case where there is a constant (or plug) flow are small. For these conditions, it is possible to use the no-flow, soft-wall radial basis functions for fitting rotating rake measured data in a soft wall duct with an assumed plug flow within some error, typically small. When a mean shear flow profile is included when numerically computing the radial basis functions, the resulting radial basis functions may be significantly different in shape. Using this numerical approach, Envia et al. ${ }^{7}$ showed an example where neglecting the presence of the real boundary layer flow in the duct resulted in a $3.2 \mathrm{~dB}$ error in computing the mode amplitude.

In addition to the effect of the flow profile on the shape of the radial basis functions, Dahl \& Sutliff ${ }^{6}$ discussed the assumption that the mode amplitude results are based on modes propagating in only one direction. Heidelberg \& $\mathrm{Hall}^{8}$ recognized that this was an issue during early development of the rotating rake measurement system. The presence of reflected modes would confuse the interpretation of the measured data. But, since the far-field noise computed from in-duct measured mode data had good agreement with measured far-field radiated noise levels, they assumed that most of the acoustic power was traveling away from the fan and stator noise sources and hence the acoustic modes behaved the same way. Nonetheless, to account for the presence of reflected mode contamination in rotating rake measured data, Cicon \& Sofrin ${ }^{9}$ developed a scheme using a finite element radiation code to produce calibration values that related the measured total sound to the sound propagating away from the source and toward the inlet or exit of the duct. They showed that depending on the location of the rotating rake measurement plane within the duct, the far-field sound levels based on that data varied over a range of $12 \mathrm{~dB}$. Using the calibration scheme, this range was reduced to a $\pm 0.5 \mathrm{~dB}$ band. Thus, the reflected mode effects could be removed from already measured data. Meyer ${ }^{10}$ further studied the effects of reflections in a fan inlet duct using a numerical code to predict the sound source coupled to a code that computes the radiated sound from within the duct. The most significant effects were found in the region where the mode cuts on. This effect was later confirmed by Nallasamy et al. ${ }^{11}$ where it was shown that mode reflections increase as cutoff was approached. The resulting changes in far-field noise levels were reported as high as $3 \mathrm{~dB}$. Prior to the results reported herein, no direct rotating rake measurements have been made to enable post-processing the measured data to separate the modes propagating in the two directions within a fan inlet or exit duct.

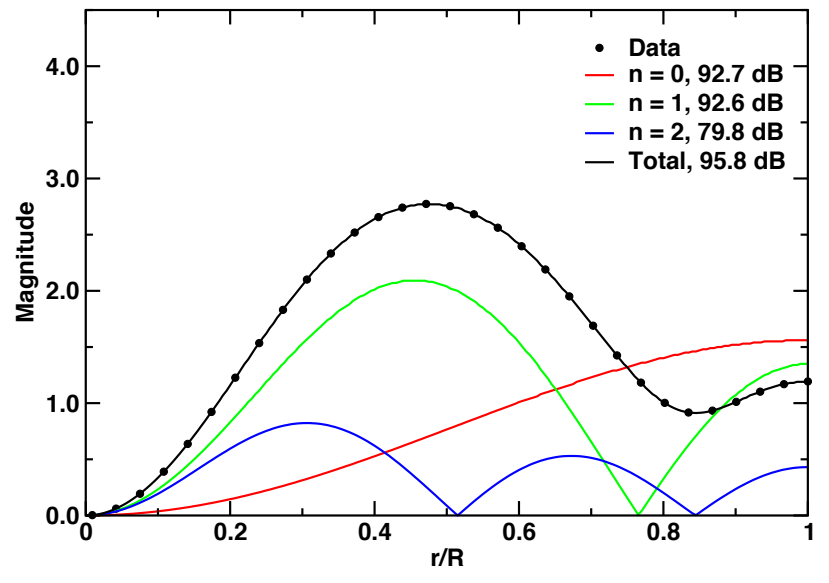

(a) Results using 1-rake analysis.

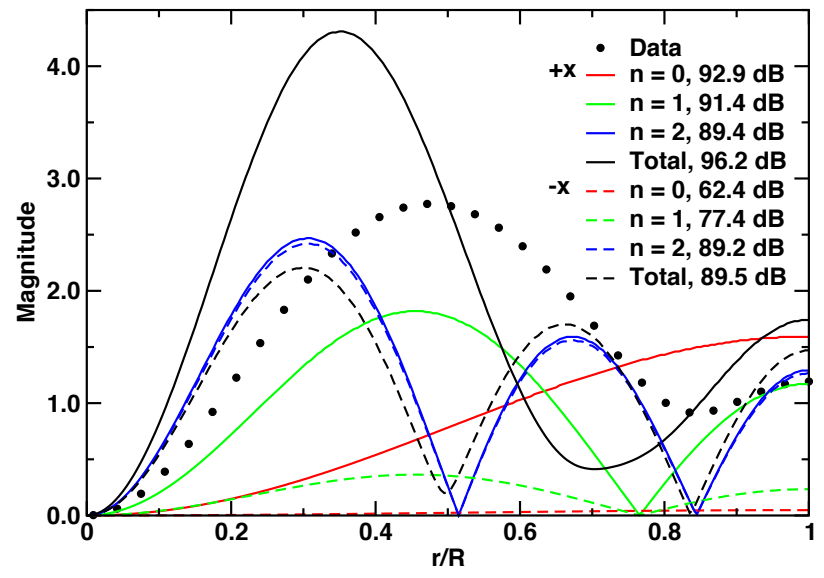

(b) Results using 2-rake analysis.

Figure 1. Comparison of mode shapes and propagating mode power levels from 1-rake and 2-rake analyses using simulated rake data in a duct with modes propagating in both directions.

An example of the effects of neglecting the reflected modes in a duct using simulated rake data is shown in Figure 1. Three modes propagating in both directions within a circular duct with different amplitudes were summed at various radial positions at different axial locations to simulate measured rake data. The data were then processed from a 1-rake system and, when a second rake is added co-rotating with the first rake, from a 2-rake system. The results for a single rake, where all the modes are assumed to be propagating 
in one direction called the $+x$ direction, are shown in Figure 1(a) in terms of the mode shapes that are labeled according to their radial order $n$ from $n=0$ to $n=2$. The sum of the three modes fits the data well. The figure also shows the mode power for each mode and the total power. Figure 1(b) has the results for the 2-rake system analysis. It shows that modes propagate in both directions. The radial modes with $n=0$ and $n=1$ have large mode amplitudes for the $+x$ direction propagating modes relative to their corresponding $-x$ direction propagating modes. Hence, the energy in these modes is largely propagating in the $+x$ direction. The modes with $n=2$, however, propagate in both directions with about the same amount of energy. The results for the 2-rake analysis shows that the total power in the $+x$ direction is $0.4 \mathrm{~dB}$ higher than that found using the 1-rake analysis; but in the 1-rake case the mode power for the $n=2$ mode propagating in the $+x$ direction was underestimated by about $10 \mathrm{~dB}$ compared to the 2-rake analysis case.

This paper extends the rotating rake measurement data analysis as described in Dahl \& Sutliff 6 to enable the separation of the modes propagating in both directions in a duct. This will provide a better tool for diagnosing the sound structure in a fan duct especially as large, modern fans are designed with shorter inlet ducts. The length of the duct, whether long or short, effects the level of reflections in the duct, as alluded to in Heidelberg \& Hall $^{8}$ and Meyer. ${ }^{10}$ The duct length also determines the amount of acoustic treatment that can be placed in the duct which can affect the amount of reflection at the exit ${ }^{12}$ and hence the amount of radiated noise. In addition to analyzing measured data, the technique may be used to post-process data from a computational aeroacoustics code. ${ }^{13}$

The governing equations for the propagation of sound in a cylindrical or annular duct are presented in the next section. The equations allow for the presence of a general parallel mean flow within the duct. Using only hard wall boundary conditions at this time, an eigenvalue problem is formed that when solved produces the eigenvalues that in general have complex axial wave numbers and hence can grow or decay with axial distance. The solution also provides the radial basis functions associated with the axial eigenvalues. This procedure is applied at each rake measurement location allowing for gradual changes in duct area and flow conditions between measurement locations. Next, a description is given of the decomposition of the measured circumferential mode amplitudes into a sum of radial basis functions representing modes propagating in both directions in the duct. Using information from two rake measurement locations, a least-squares fitting procedure is described that separates the directionally-dependent mode amplitudes. The fitting procedure is also arranged to handle evanescent modes. Finally, the method is tested using simulated data and some preliminary data from both measurements and numerical calculations.

\section{Numerical Solution}

The goal of analyzing rotating rake data from 2 rakes is to obtain the amplitudes of the measured modes that propagate in both directions in the duct. Once the mode amplitudes are found, the acoustic power in each mode can be computed. For that to occur, two basic processes are followed: 1) determine the radial basis functions by numerically solving the eigenvalue problem presented by the governing equation and 2) determine the mode amplitudes by a least-squares fit using a system of equations representing modes propagating in both directions in the duct. The presence of evanescent modes are also accommodated in the fit.

\section{II.A. Eigenvalue Problem}

The numerical analysis of the eigenvalue problem is based on a discretization of the third order equation for the acoustic pressure $p$ derived from combining the linearized momentum and energy equations, and assuming the static pressure is constant.

$$
\frac{\mathrm{D}^{3} p}{\mathrm{D} t^{3}}+c^{2}\left[2 \frac{\partial(c M)}{\partial r} \frac{\partial^{2} p}{\partial x \partial r}-\frac{1}{c^{2}} \frac{\partial c^{2}}{\partial r} \frac{\mathrm{D}}{\mathrm{D} t} \frac{\partial p}{\partial r}-\frac{\mathrm{D}}{\mathrm{D} t} \nabla^{2} p\right]=0
$$

where

$$
\frac{\mathrm{D}}{\mathrm{D} t}=\frac{\partial}{\partial t}+c M \frac{\partial}{\partial x}
$$

and $\nabla^{2}$ is the Laplace operator in cylindrical coordinates. This equation accounts for the compressibility of the flow and allows both the Mach number $M$ and the speed of sound $c$ to be functions of the radial direction. 
For the computational and experimental results presented in this paper, the duct walls for both circular and annular geometries are hard. Hence the boundary condition at the wall, given in terms of the acoustic pressure, is

$$
\frac{\partial p}{\partial r}=0
$$

For a circular duct, the boundary condition at the duct centerline, $r=0$, is given by

$$
\begin{aligned}
\frac{\partial p}{\partial r} & =0 & & m=0 \\
p & =0 & & m \neq 0
\end{aligned}
$$

where $m$ is the circumferential mode number.

The analysis of equation (1) starts by using the separation of variables solution form for the acoustic pressure

$$
p(x, \theta, r, t)=p_{m n} E_{m n}(r) e^{-j(\omega t-m \theta-k x)}
$$

where we let $E_{m n}$ be a general function of $r$ that forms the basis function for the least-squares fit, $\omega$ is the radian frequency, and $k$ is the axial wave number which also depends on $m$, the circumferential mode number, and $n$, the radial mode number. The $x$-axis is positive in the direction out of the duct away from the sound source within the duct. Since equation (1) is linear, it can be solved using one mode at a time. Substitute equation (4) into equation (1) and divide out the exponential function and the amplitude coefficient to obtain an equation that is used to determine the shape of the radial basis function $E$ for each pair of $(m, n)$ mode numbers.

$$
\begin{aligned}
{\left[1-c M \frac{k}{\omega}\right]^{3} E } & +\frac{c^{2}}{\omega^{2}}\left(2 \frac{k}{\omega} \frac{\partial(c M)}{\partial r} \frac{\partial E}{\partial r}+\frac{1}{c^{2}} \frac{\partial c^{2}}{\partial r}\left[1-c M \frac{k}{\omega}\right] \frac{\partial E}{\partial r}\right. \\
& \left.+\left[1-c M \frac{k}{\omega}\right]\left[\frac{\partial^{2} E}{\partial r^{2}}+\frac{1}{r} \frac{\partial E}{\partial r}-\frac{m^{2}}{r^{2}} E-k^{2} E\right]\right)=0
\end{aligned}
$$

With boundary conditions defined by equations (2) and (3), the resulting equation becomes an eigenvalue problem where the eigenvalue is the complex axial wave number and the radial basis functions no longer have the form of Bessel functions, that were found for the previous closed form solutions, when a real boundary layer flow is in the duct. Using finite difference approximations, equation (5) is discretized using $N+1$ nodes resulting in a matrix equation that, including the appropriate boundary conditions, is written as

$$
\mathbf{D}_{3}(k) \mathbf{E}=0
$$

where $\mathbf{D}_{3}(k)$ is a lambda matrix of degree three representing a scalar polynomial with matrix coefficients

$$
\mathbf{D}_{3}(k)=\mathbf{C}_{0} k^{3}+\mathbf{C}_{1} k^{2}+\mathbf{C}_{2} k+\mathbf{C}_{3}
$$

and $\mathbf{E}$ is the vector of radial basis function values at each node point. The procedure from here to solve equation (6) is found in Dahl \& Sutliff. ${ }^{6}$

The eigenvalues produced in the solution of equation (6) are associated with all the modes that can propagate and/or decay in both directions in the duct. Since follow-on analysis requires separating the modes that propagate and/or decay in both directions, the eigenvalues must be identified from the global set produced. Noting the sign convention used for the exponential functions in equation (4) and the $x$-axis direction, the following definitions are used to identify the eigenvalues. If $k$ is complex or pure imaginary, then the eigenvalues appropriate for propagation in the $+x$ or $-x$ directions are those that decay in the direction of propagation. These are identified by evaluating the imaginary part of $k$ using the conditions

$$
\begin{array}{ll}
\Im\{k\}>0 & \text { decay in }+x \text { direction } \\
\Im\{k\}<0 & \text { decay in }-x \text { direction }
\end{array}
$$

If $k$ is real, then the group velocity $c_{g}=\partial \omega / \partial k$ is computed to indicate the direction of propagation.

$$
\begin{array}{ll}
c_{g}>0 & \text { propagation in }+x \text { direction } \\
c_{g}<0 & \text { propagation in }-x \text { direction }
\end{array}
$$


Using $c_{g}$ to determine the propagation direction takes into account the effect that a mean flow has on the propagation.

The radial basis functions produced from solving equation (6) are functions of the radius even though they are associated with the axial eigenvalue. The ordering of these functions coming out of the matrix equation follow the ordering of the axial eigenvalue. The lowest order radial basis function is associated with the axial eigenvalue with the lowest magnitude with the order following the increasing magnitude of the axial eigenvalue. This is not necessarily the ordering that would be followed if a radial eigenvalue existed for the general mean flow case given by equation (5). For mean flows that are fairly constant except near the walls, we expect the radial basis functions to be similar to those for a constant mean flow. Therefore, the radial basis functions are ordered following the magnitude of a radial eigenvalue term $\kappa$ determined from

$$
\kappa^{2}=\left(\frac{\omega}{\mathrm{c}}-\mathrm{M} k\right)^{2}-k^{2}
$$

where $\mathrm{M}$ and $\mathrm{c}$ are the average Mach number and speed of sound values across the duct cross-sectional area.

\section{II.B. Wave Propagation Direction}

The measured rotating rake microphone data are analyzed for 1 rake, as described in Sutliff, ${ }^{3}$ and for 2 rakes, as described in the Appendix of this paper, to obtain the total circumferential mode amplitude $C_{m}^{s}\left(r_{i}\right)$ at each radial measurement location $r_{i}$ prior to further decomposition using the radial basis functions. That is,

$$
C_{m}^{s}\left(r_{i}\right)=\sum_{n=0}^{N_{\max }-1} P_{s m n} E_{s m n}\left(r_{i}\right) \quad i=1,2, \ldots, N_{\text {meas }}
$$

where $N_{\text {meas }}$ is the number of radial measurement points and $s$ is the harmonic number of the blade-passing frequency (See the Appendix). It has been assumed that in solving equation (11) for the mode amplitudes $P_{s m n}$, using $N_{\max }$ radial mode shapes, that the mode propagates in only one direction. As discussed in the Introduction, this is not, in general, the case. Following Åbom, ${ }^{14}$ Akoum \& Ville, ${ }^{15}$ and Schultz et al., ${ }^{16}$ the $P_{s m n}$ term is a function of the axial location $x$ as in the exponential term in equation (4) and is written as

$$
P_{s m n}(x)=P_{s m n}^{+} e^{j k x}+P_{s m n}^{-} e^{-j k x}
$$

where $P_{s m n}^{+}$and $P_{s m n}^{-}$are the modal amplitudes for the modes propagating in the $+x$ direction and the $-x$ direction, respectively, and where the subscripts $s, m$, and $n$ have been dropped from the $k$ term. Taking data at two axial locations, $x_{B}$ and $x_{A}$, Rademaker $^{17}$ and Akoum \& Ville ${ }^{15}$ ) results in a system of equations

$$
\begin{aligned}
& P_{s m n}\left(x_{B}\right)=P_{s m n}^{+} e^{j k x_{B}}+P_{s m n}^{-} e^{-j k x_{B}} \\
& P_{s m n}\left(x_{A}\right)=P_{s m n}^{+} e^{j k x_{A}}+P_{s m n}^{-} e^{-j k x_{A}}
\end{aligned}
$$

that can be solved for $P_{s m n}^{+}$and $P_{s m n}^{-}$using a least-squares fit method.

This approach has assumed constant conditions in the duct and that all modes to be included in the least-squares fit are propagating. In general, information related to evanescent modes may be included in rake measured data depending on the axial location of the measurement. As an extreme example using equation (13), the wavenumber $k$ could represent an evanescent or a damped mode decaying in the $+x$ direction going from $x_{B}$ to $x_{A}$. The mode could be sufficiently damped by reaching $x_{A}$ that the exponential function would be zero. This results in the matrix of coefficients multiplying the amplitudes $P_{s m n}^{+}$and $P_{s m n}^{-}$ containing a subcolumn of zeroes that leads to a singular matrix when computing the normal equation for the least-squares fit.

To allow for the proper fitting of evanescent modes within the fit process, we use the approach given by Ovenden \& Rienstra. ${ }^{18}$ The measured circumferential mode amplitudes are written as the sum of radial basis functions as follows:

$$
\begin{aligned}
C_{m}^{s}\left(x_{B}, r_{i}\right)= & \sum_{n=0}^{N_{\max }-1}\left[P_{s m n}^{+} E_{s m n}^{+}\left(r_{i} ; x_{B}\right) e^{j k_{B}^{+} x_{B}}+P_{s m n}^{-} E_{s m n}^{-}\left(r_{i} ; x_{B}\right) e^{j k_{B}^{-} x_{B}}\right] \\
C_{m}^{s}\left(x_{A}, r_{i^{\prime}}^{\prime}\right) e^{-j m \phi}= & \sum_{n=0}^{N_{\max }-1}\left[P_{s m n}^{+} E_{s m n}^{+}\left(r_{i^{\prime}}^{\prime} ; x_{A}\right) e^{j k_{A}^{+} x_{A}}+P_{s m n}^{-} E_{s m n}^{-}\left(r_{i^{\prime}}^{\prime} ; x_{A}\right) e^{j k_{A}^{-} x_{A}}\right] \\
& i=1,2, \ldots, N_{B} \quad i^{\prime}=1,2, \ldots, N_{A}
\end{aligned}
$$


where $\phi$ is the azimuthal offset between the rake at $x_{B}$ and the rake at $x_{A}$ as described in the Appendix. Rearranging, we get

$$
\begin{aligned}
C_{m}^{s}\left(x_{B}, r_{i}\right) & =\sum_{n=0}^{N_{\max }-1}\left[\left\{P_{s m n}^{+} e^{j k_{B}^{+} x_{B}}\right\} E_{s m n}^{+}\left(r_{i} ; x_{B}\right)+\left\{P_{s m n}^{-} e^{j k_{A}^{-} x_{A}}\right\} E_{s m n}^{-}\left(r_{i} ; x_{B}\right) e^{j\left(k_{B}^{-} x_{B}-k_{A}^{-} x_{A}\right)}\right] \\
C_{m}^{s}\left(x_{A}, r_{i^{\prime}}^{\prime}\right) e^{-j m \phi} & =\sum_{n=0}^{N_{\max }^{-1}}\left[\left\{P_{s m n}^{+} e^{j k_{B}^{+} x_{B}}\right\} E_{s m n}^{+}\left(r_{i^{\prime}}^{\prime} ; x_{A}\right) e^{j\left(k_{A}^{+} x_{A}-k_{B}^{+} x_{B}\right)}+\left\{P_{s m n}^{-} e^{j k_{A}^{-} x_{A}}\right\} E_{s m n}^{-}\left(r_{i^{\prime}}^{\prime} ; x_{A}\right)\right]
\end{aligned}
$$

This formulation:

- Acknowledges the axial eigenvalues and the radial basis functions in the upstream propagating direction are different from those in the downstream propagating direction when flow is present.

- Allows for small changes in flow and duct area with axial distance. Thus we let ${ }^{18}$

$$
\int_{x_{B}}^{x_{A}} k \mathrm{~d} x \approx k_{A} x_{A}-k_{B} x_{B}
$$

for $\left|k_{A}-k_{B}\right|$ much less than both $\left|k_{A}\right|$ and $\left|k_{B}\right|$.

- Rescales the amplitudes and radial basis functions to properly handle evanescent modes.

- Unlike equation (13), the axial eigenvalues in equation (15) are possibly different in the two directions. Hence $k^{+}$and $k^{-}$contain the appropriate signs for propagation and/or decay in the indicated direction as obtained from the solution of equation (6).

\section{II.C. Least-Squares Fit}

The microphone data from the rotating rakes are Fourier analyzed to obtain complex values $C_{m}^{s}\left(x, r_{i}\right)$ that represent the separation of the acoustic pressure by frequency and circumferential mode order at each radial location, $r_{i}$, of the microphone. These values are expected to be functions of the radial mode content in the duct following equation (15) that represents the attempt to further decompose the measured circumferential mode data into an approximate series of weighted radial basis functions for modes propagating and/or decaying in both directions within the duct. To solve equation (15) for the complex radial mode amplitudes, we use the least-squares method. The solution is to minimize the residual sum of squares

$$
e=\|\mathbf{c}-\mathbf{B P}\|_{2}^{2}
$$

where

$$
\mathbf{c}=\left[\begin{array}{llllll}
C_{m}^{s}\left(x_{B}, r_{1}\right) & \ldots & C_{m}^{s}\left(x_{B}, r_{N_{B}}\right) & C_{m}^{s}\left(x_{A}, r_{1}^{\prime}\right) e^{-j m \phi} & \ldots & C_{m}^{s}\left(x_{A}, r_{N_{A}}^{\prime}\right) e^{-j m \phi}
\end{array}\right]^{\mathrm{T}}
$$

is a vector of length $n_{p}=N_{B}+N_{A}$ comprised of the measured complex circumferential mode data,

$$
\mathbf{B}=\left[\begin{array}{ccc}
E_{s m 0}^{+}\left(r_{1} ; x_{B}\right) & E_{s m 0}^{-}\left(r_{1} ; x_{B}\right) e^{j\left(k_{B}^{-} x_{B}-k_{A}^{-} x_{A}\right)} & \ldots \\
\vdots & \vdots & \ldots \\
E_{s m 0}^{+}\left(r_{N_{B}} ; x_{B}\right) & E_{s m 0}^{-}\left(r_{N_{B}} ; x_{B}\right) e^{j\left(k_{B}^{-} x_{B}-k_{A}^{-} x_{A}\right)} & \ldots \\
E_{s m 0}^{+}\left(r_{1}^{\prime} ; x_{A}\right) e^{j\left(k_{A}^{+} x_{A}-k_{B}^{+} x_{B}\right)} & E_{s m 0}^{-}\left(r_{1}^{\prime} ; x_{A}\right) & \cdots \\
\vdots & \vdots & \cdots \\
E_{s m 0}^{+}\left(r_{N_{A}}^{\prime} ; x_{A}\right) e^{j\left(k_{A}^{+} x_{A}-k_{B}^{+} x_{B}\right)} & E_{s m 0}^{-}\left(r_{N_{A}}^{\prime} ; x_{A}\right) & \cdots
\end{array}\right]
$$

is a matrix of size $n_{p} \times n_{c}, n_{c}=2 N_{\max }$, containing complex coefficients derived from the radial basis functions, and

$$
\mathbf{P}=\left[\left\{P_{s m 0}^{+} e^{j k_{B}^{+} x_{B}}\right\} \quad\left\{P_{s m 0}^{-} e^{j k_{A}^{-} x_{A}}\right\} \quad\left\{P_{s m 1}^{+} e^{j k_{B}^{+} x_{B}}\right\} \quad\left\{P_{s m 1}^{-} e^{j k_{A}^{-} x_{A}}\right\} \quad \ldots\right]^{\mathrm{T}}
$$


is the solution vector of length $n_{c}$ for the complex radial mode amplitudes. By ensuring that the number of measurement points $N_{B}+N_{A}$ is greater than twice the number of radial basis functions $N_{\max }$, the problem is overdetermined, $n_{p}>n_{c}$, and a solution to this linear problem is easily computed using the singular value decomposition method. This method provides the best approximation to solving the linear least-squares problem for over-determined systems and it is robust, handling problems where $\mathbf{B}$ is close to being singular. (See Lawson \& Hanson ${ }^{19}$ for details.)

\section{Testing the Method}

The technique to analyze data from 2 rotating rakes was initially tested using simulated data. This exercised the basic concepts and algorithms of the technique. Some preliminary data from in-duct measurements and computations were also available for testing.

\section{III.A. Simulated Data}

Simulated data was used to test the analysis technique to separate the direction of modes propagating in a duct. The simulated data was constructed from a set of Bessel function modes in a circular duct propagating at a single frequency. Following equation (14), we used

$$
C_{m}(x, r)=\sum_{n=0}^{N_{\max }-1}\left(P_{m n}^{+} E_{m n}^{+}(r) e^{j k x}+P_{m n}^{-} E_{m n}^{-}(r) e^{-j k x}\right)
$$

to obtain the circumferential mode amplitudes where

$$
E_{m n}^{+}(r)=E_{m n}^{-}(r)=\sqrt{\mathcal{N}_{m}^{2}} \mathrm{~J}_{m}\left(\kappa_{n} r\right)
$$

and

$$
\mathcal{N}_{m}^{2}=\left[\left(1-\frac{m^{2}}{\kappa_{n}^{2}}\right) \mathrm{J}_{m}\left(\kappa_{n}\right)^{2}\right]^{-1}
$$

give us the radial basis functions for a constant area, circular duct with no mean flow. The factor $\mathcal{N}$ is used to normalize the Bessel function $\mathrm{J}_{m}$ and ensures that the integral of $E^{2}$ across the area of the duct equals the duct cross-sectional area. This is the power-based form of normalization that allows meaningful comparisons of the mode amplitudes. ${ }^{5}$

Equation (17) was used to compute the circumferential mode amplitude for a single propagating mode in the $+x$ direction at a frequency of $480 \mathrm{~Hz}$ with $m=2, n=0, P_{20}^{+}=1.0, \kappa_{0}=3.054$, and $k_{0}=4.355$ combined with a mode reflected into the $-x$ direction with amplitude $P_{20}^{-}=0.98$. In this example, the axial wave number is real resulting in the mode propagating without any decrease in the mode amplitude. The mode amplitudes remain the same at every axial location for both the $+x$ and $-x$ direction propagating modes. The combination of the two modes creates a standing wave with an amplitude computed from the sum of the $+x$ and $-x$ direction propagating modes.

$$
A_{n}(x)=\left|P_{m n}^{+} e^{j k x}+P_{m n}^{-} e^{-j k x}\right|
$$

If the reflecting point is at $x=0, A_{n}(x=0)$ is at a maximum value and decreases for $x<0$ until a minimum is reached, then increases again as shown in Figure 2. A single measurement rake placed at the maximum of the standing wave $(x=0)$ will provide the data that when analyzed according to the single rake procedure will return the amplitude of the standing wave. As shown in Figure 2, as the rake is moved in the $-x$ direction to 6 other locations, the data provided to the 1-rake analysis reproduced the local standing wave amplitude.

To perform the 2-rake analysis, the data at $x=0$ is considered to be the $x_{A}$ position for the purposes of solving the system given by equation (15). The $x_{B}$ position is then given, in turn, by each of the other 6 positions. The 2-rake analysis shows the amplitudes of the two modes being separated with a $+x$ direction mode amplitude of $P_{20}^{+}=1.0$ and a $-x$ direction mode amplitude of $P_{20}^{-}=0.98$. Note that the levels measured by the rake at position $x_{A}$ are higher than at any $x_{B}$ position. As a check to see if the results would be affected if the levels of the fixed position rake at $x_{A}$ were lower than the levels at the $x_{B}$ position, the standing wave was shifted and the analysis repeated. Figure 2 shows the amplitudes of the $+x$ and $-x$ 


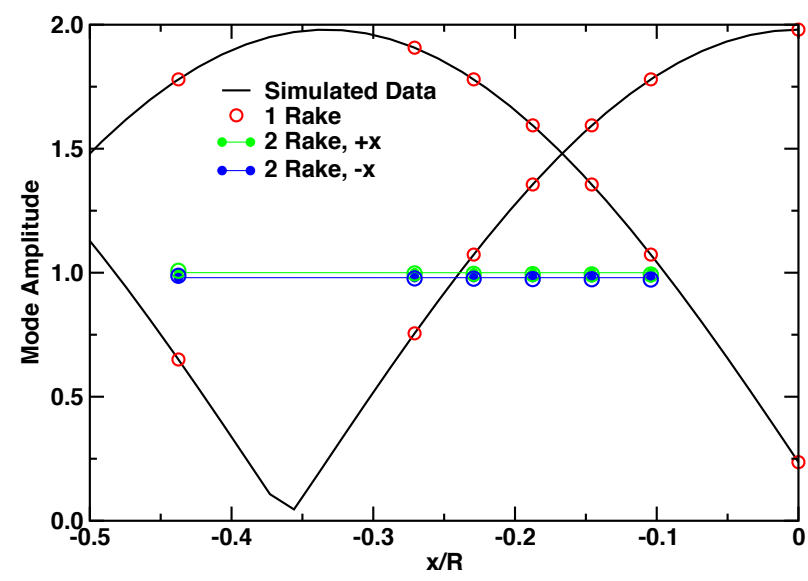

Figure 2. Comparison of 1-rake and 2-rake analyses for mode amplitude using simulated rake data with 1 propagating mode in both directions. $480 \mathrm{~Hz}, m=2, n=0$, $P_{20}^{+}=1.0, P_{20}^{-}=0.98$.

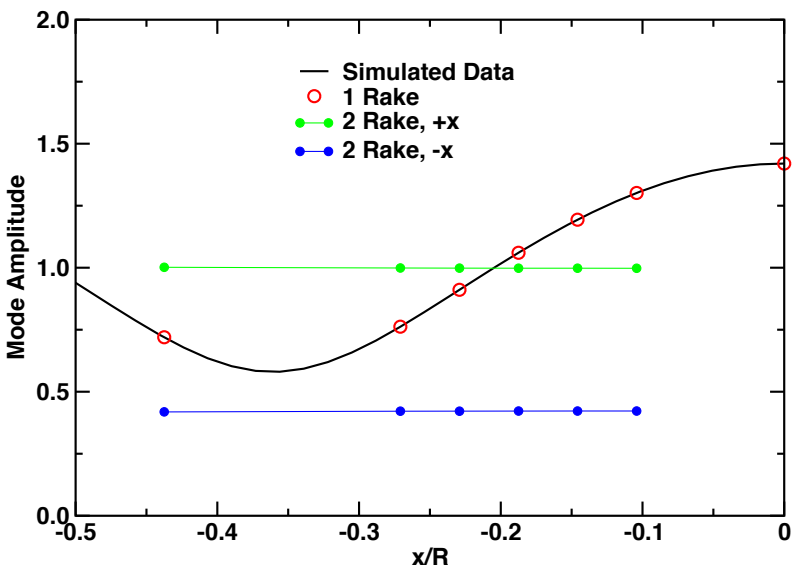

Figure 3. Comparison of 1-rake and 2-rake analyses for mode amplitude using simulated rake data with 1 propagating mode in both directions. $480 \mathrm{~Hz}, m=2, n=0$ $P_{20}^{+}=1.0, P_{20}^{-}=0.42$.

direction modes remain unchanged. Thus, ideally it does not matter where the two measurement positions are located relative to the standing wave pattern in order to recover the directional mode amplitudes. In practical measurements, limitations do exist. ${ }^{14}$ These will be explored as the experimental method is developed. Another example is shown in Figure 3 where the level of the reflected mode is lower.

A more complicated simulated data example is shown next. Setting $m=2$, the circumferential mode amplitudes representing the extracted data from a rotating rake measurement are computed using the coefficients shown in Table 1. The magnitude of the axial eigenvalues are the same in both directions. The

\begin{tabular}{|c|c|c|c|c|c|}
\hline$n$ & $k_{n}$ & $\kappa_{n}$ & $\left|P_{2 n}^{+}\right|$ & $\left|P_{2 n}^{-}\right|$ & $\xi_{n}$ \\
\hline 0 & 10.368 & 3.054 & 1.204 & 0.036 & 3.539 \\
1 & 8.477 & 6.706 & 1.118 & 0.224 & 1.612 \\
2 & 4.175 & 9.969 & 1.266 & 1.241 & 1.084 \\
3 & $j 7.526$ & 13.170 & 0.000 & $0.1^{(*)}$ & 0.821 \\
\hline
\end{tabular}

(*) at reference location $x / R=-0.083$

Table 1. Eigenvalues, mode amplitudes, and cutoff ratios for a simulation with 3 propagating modes in both directions and 1 damped mode in the $-x$ direction. $960 \mathrm{~Hz}, m=2$.

three lower order radial modes are propagating in both directions with cutoff ratios $\xi_{n}=\omega R / \kappa_{n} c$ greater than 1 and there is one cut off mode decaying in the $-x$ direction with a reference amplitude of 0.1 at $x / R=-0.083$. Figure 4 shows the 1-rake analysis of the data giving the computed mode amplitudes as a function of the axial location. These results are compared to standing-wave amplitudes, equation (18). The comparison is identical. The analysis also obtains the correct damped mode amplitude. Obviously, the assumption for 1-rake operation that modes only propagate in one direction $(+x$ in this case) requires significantly reduced mode amplitudes in the other direction. The $n=0$ mode has a $-x$ direction mode with an amplitude two orders of magnitude smaller than the $+x$ direction mode amplitude and still shows a small oscillation about the $\left|P_{20}^{+}\right|=1.204$ value.

Mode amplitude results for 2-rake analysis are shown in Figures 5 and 6 . Rake B is fixed at $x_{B} / R=-0.83$ and Rake A data is varied as a function of $x$. Figure 5 shows the variation in mode amplitudes where only the three propagating modes in each direction are included in the analysis. There are large variations in mode amplitude for the $n=2$ modes near $x=0$. These become much smaller for the other modes where the amplitudes of the $-x$ direction propagating modes are much smaller than the $+x$ direction propagating modes. In the simulation, modes may be considered to be propagating in the $+x$ direction, encountering a barrier at $x=0$, and reflecting back off that barrier. In addition to the three reflected or $-x$ direction propagating modes, the simulation included the creation of an evanescent or a damped mode at $x=0$ that decays in the $-x$ direction. When this damped mode is included in the 2-rake analysis, all propagating 


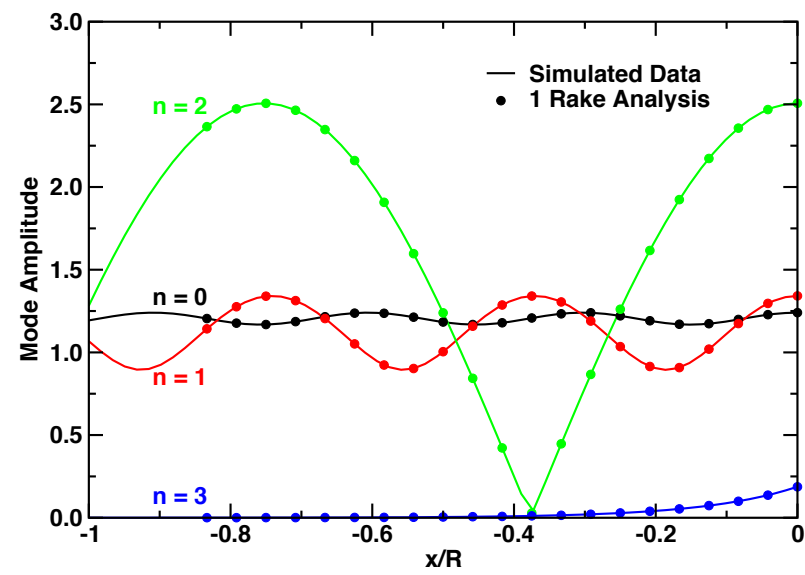

Figure 4. Comparison of 1-rake analysis for mode amplitude to the standing wave amplitude for 3 propagating waves in both directions and 1 damped mode. $960 \mathrm{~Hz}$, $m=2$.

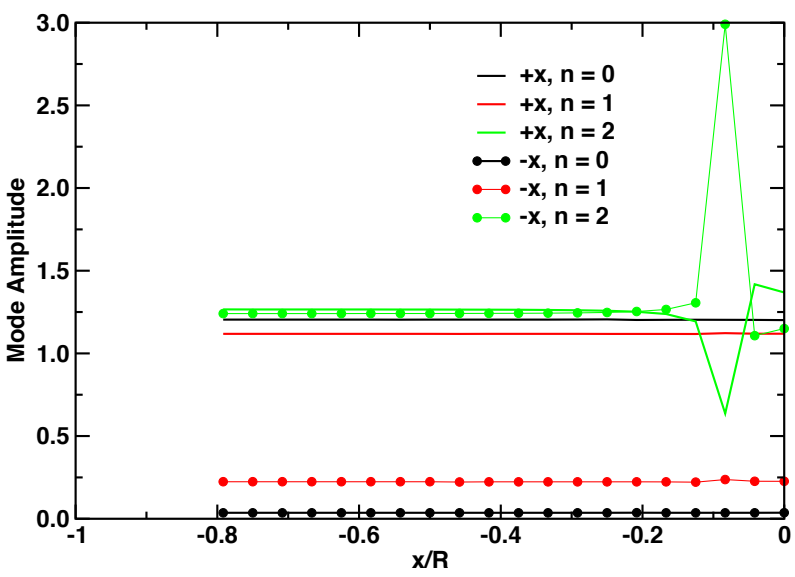

Figure 5. Mode amplitudes from 2-rake analysis of the same simulated data as in Figure 4 using only 3 propagating modes in both directions in the fit process. $960 \mathrm{~Hz}$, $m=2$.

modes are found to have constant mode amplitudes everywhere in the duct as shown in Figure 6 . The damped mode amplitude is also determined. Thus, the variations in mode amplitudes seen in the right side of Figure 5 are not due to any issues between incident and reflected modes; but by the fit process trying to put energy into propagating modes that belongs to a damped mode.

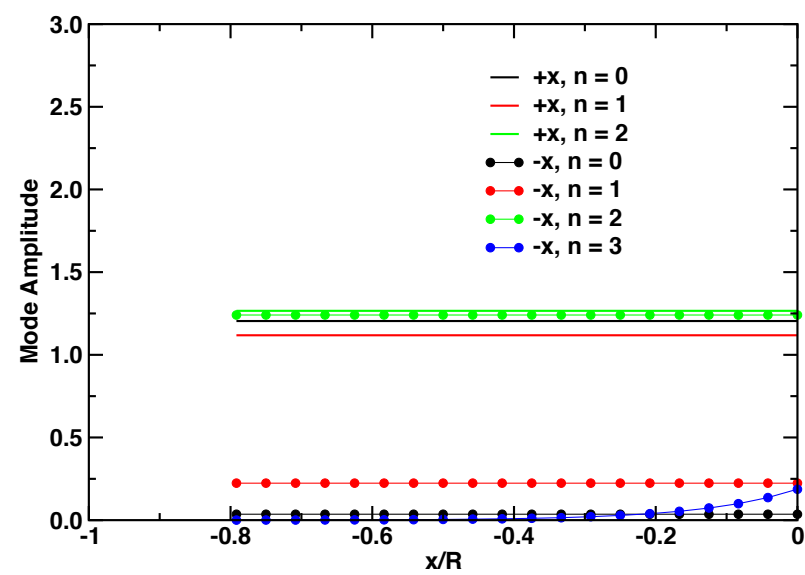

Figure 6. Mode amplitudes from 2-rake analysis of the same simulated data as in Figure 4 using 3 propagating modes in both directions and 1 damped mode in the fit process. $960 \mathrm{~Hz}, m=2$.

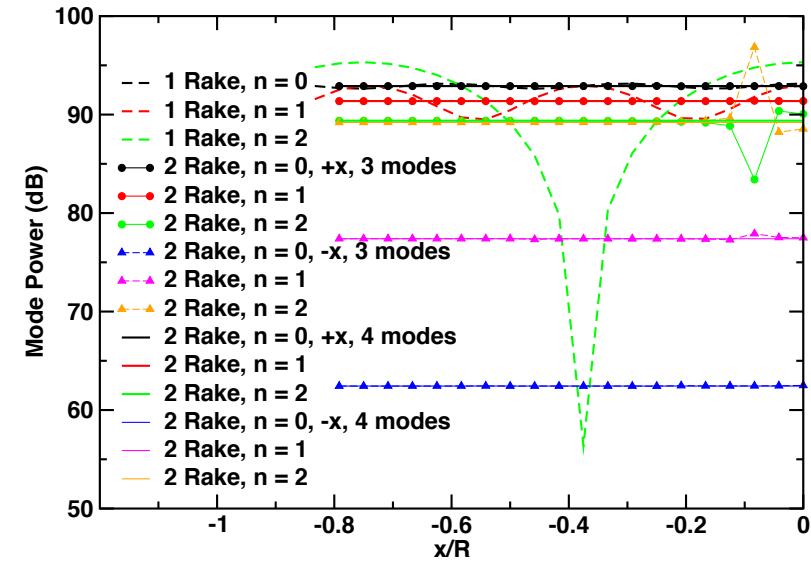

Figure 7. Comparison of the mode power levels computed for the results shown in Figures 4 to 6 .

Figure 7 shows the computed mode power levels for each of the three analysis scenarios shown in Figures 4 to 6 . The variations in the mode power levels as a function of the axial location follow the variations in the mode amplitudes. The accuracy of the 1-rake analysis is more easily discerned. When the $-x$ direction, $n=0$ mode is $30 \mathrm{~dB}$ lower than the $+x$ direction mode, the 1 -rake measured data can be used to determine mode power within $\pm 0.3 \mathrm{~dB}$. The $n=1,-x$ direction mode is $14 \mathrm{~dB}$ less than the $+x$ direction mode giving a -2.0 to $+1.5 \mathrm{~dB}$ range of error. The error range gets much larger with higher $-x$ direction mode power levels as shown in Table 2, for example see the 1-rake analysis for the $n=2$ mode. The table also shows the significant error in mode power if non-propagating modes are not properly taken into account, in this case as high as $7.3 \mathrm{~dB}$ for the 2-rake, 3-mode analysis for the $n=2$ mode.

\section{III.B. Measured Data}

The Advanced Noise Control Fan $^{20}$ (ANCF) is a highly configurable 4-foot diameter ducted fan located in the Aero-Acoustic Propulsion Laboratory (AAPL) at the NASA Glenn Research Center. The AAPL is a hemispherical, anechoic (above $125 \mathrm{~Hz}$ ) test facility used for noise measurements. In order to provide a 


\begin{tabular}{|c|c|c|c|c|c|c|c|}
\hline Type of Analysis & direction & $n=0$ & error range & $n=1$ & error range & $n=2$ & error range \\
\hline $1 \operatorname{Rake}^{(*)}$ & $+x$ & 92.9 & $(-0.3,+0.3)$ & 91.5 & $(-2.0,+1.5)$ & 89.7 & $(-33.3,+5.6)$ \\
\hline 2 Rakes, 3 modes ${ }^{(*)}$ & $+x$ & 92.9 & - & 91.4 & - & 89.1 & $(-5.7,+0.7)$ \\
\hline 2 Rakes, 3 modes ${ }^{(*)}$ & $-x$ & 62.4 & - & 77.4 & $(-0.1,+0.5)$ & 89.5 & $(-1.3,+7.3)$ \\
\hline 2 Rakes, 4 modes & $+x$ & 92.9 & - & 91.4 & - & 89.4 & - \\
\hline 2 Rakes, 4 modes & $-x$ & 62.4 & - & 77.4 & - & 89.2 & - \\
\hline
\end{tabular}

(*) Mode powers are averaged over all axial locations.

Table 2. Propagating mode powers and error ranges in decibels computed after 1-rake and 2-rake analyses of simulated data with 3 propagating modes in both directions and 1 damped mode in the $-x$ direction. $960 \mathrm{~Hz}, m=2$.

clean, cylindrical duct, for this experiment, the ANCF spool pieces were stacked up in a vertical orientation providing a constant area cylindrical duct. The entire stack rested on the floor with approximately 6 inches of foam material placed in the bottom of the stack to minimize reflections from the floor. For this test, a flow lip was attached to the duct exit as shown schematically in Figure 8.

The Configurable Fan Artificial Noise System (CFANS) was utilized to generate and control circumferential modes. The system consists of 4 axially distributed rows, each containing 16 electromagnetic drivers distributed around the circumference. There are two spools pieces, each having 2-rows of flush mounted drivers on the wall. A Labview ${ }^{\mathrm{TM}}$ program is used to generate the signals sent to each driver independently, in the proper relationship, to generate the desired circumferential mode. The signals to each row can be adjusted globally to effect the radial distribution, if desired. For this experiment, only a single row was actuated, the row closest to the floor. The practical limits of the system are circumferential mode orders up to \pm 7 and a maximum frequency of $1500 \mathrm{~Hz}$.

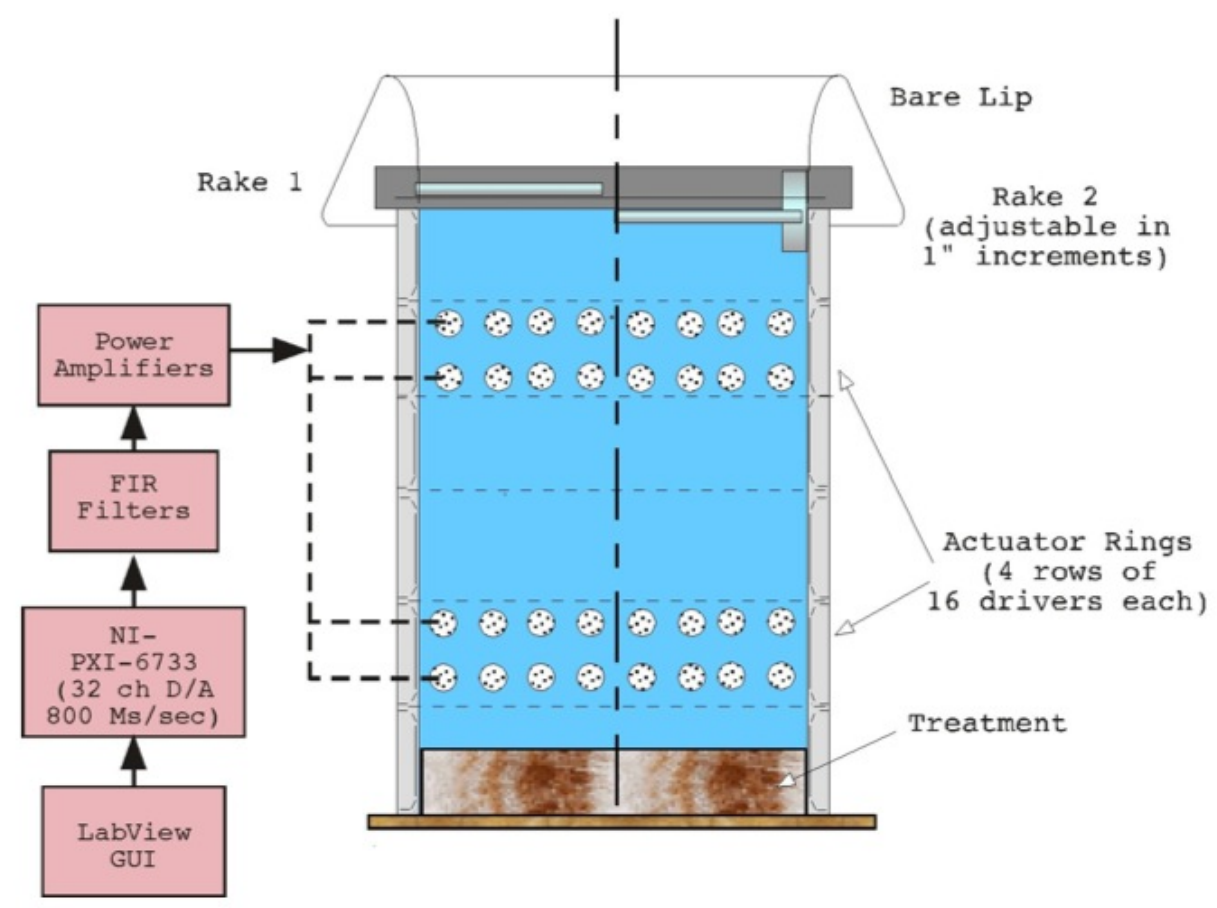

Figure 8. Schematic diagram of the Advanced Noise Control Fan duct with Configurable Fan Artificial Noise System and rotating rakes installed.

The modes were measured by the Rotating Rake mode measurement system. ${ }^{3}$ Typically, a single rake, extending from the outer-wall to the duct center-line, has been mounted to measure the modes. Since measurements at a single axial location will not be able to account for reflections in the duct, an additional 

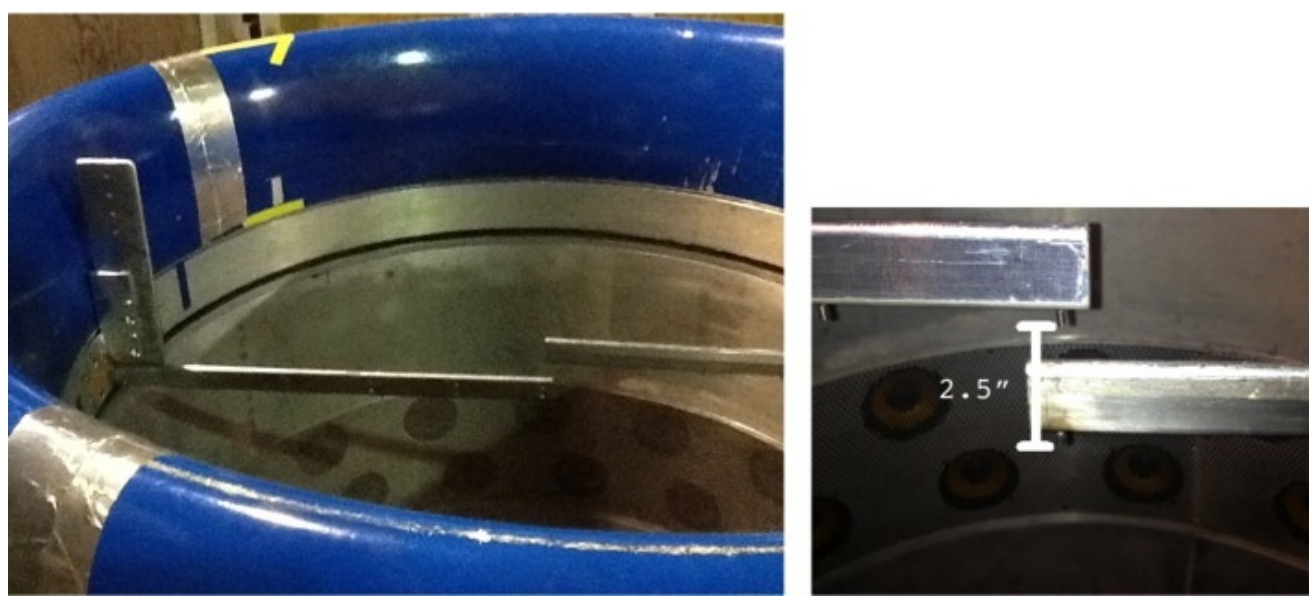

Figure 9. Pictures of the two rotating rakes installed near the lip of the duct and a close-up of the rakes with a 2.5 inch separation distance.

rake was mounted for the experiment on the same rotating ring as the original as shown in the left side of Figure 9. This second rake was adjustable in the axial direction over the range of 2.5 to 10.5 inches, in fixed, one-inch increments, and was mounted 180 degrees in the circumferential direction from the original rake, which remains fixed in the axial direction at a location designated as the origin of the $x$-axis pointing outward from the duct. Figure 9 also shows a close up picture of the separation between the rakes.

The CFANS drivers were set to generate a circumferential mode at $m=2$ with a frequency of $480 \mathrm{~Hz}$. Under these conditions only 1 mode propagates in the ANCF duct, the $(2,0)$ mode. These are the same conditions used to simulate data for the results shown in Figure 2. Initially, the flow lip is attached to the duct exit. The lip tends to minimize the reflection of sound within the duct and allows most of the sound generated in the duct to propagate out of the duct. The results for mode amplitudes from 1-rake analysis using data from both the fixed rake (Rake 1 shown in Figure 8) and the movable rake (Rake 2) are shown in Figure 10. The mode amplitudes from the fixed rake data with the lip exit in place are plotted as a function of the movable rake location (See the open circular symbols.) and give an indication of the repeatability of the measurement. The fixed rake mode amplitude is $19.24 \pm 0.09$. At each of the 6 movable rake locations, the data for the two rakes are collected simultaneously and used to perform the 2-rake analysis. The results show a fairly constant mode amplitude in both propagation directions with $\left|P_{20}^{+}\right|=18.76 \pm 0.45$ and $\left|P_{20}^{-}\right|=2.82 \pm 0.21$.

The other set of mode amplitude results shown in Figure 10 are for the same sound conditions and set of measurements but with the lip removed from the duct leaving just the mounting flange at the duct exit. It was expected that the sound would more readily reflect back into the duct with this exit condition. The results show from the 2-rake analysis that the reflected mode amplitude doubled, $\left|P_{20}^{-}\right|=5.89 \pm 0.29$, compared to the reflected mode amplitude with the lip in place. The final comparison shown in Figure 10 shows the standing wave amplitude computed from equation (18) versus the mode amplitude from the 1-rake analysis of the movable rake data with the flange condition at the duct exit. As discussed for the simulated data results shown in Figures 4 and 5, the 1-rake analysis produces the standing wave amplitude when a single rake measures data in a duct with modes propagating in both directions. The experimental results verify the simulated results.

Table 3 compares the mode power results for the conditions and results just discussed for Figure 10. The movable rake mode power levels indicate the variable range of levels that would occur in radiated noise levels when using only 1 rake, as discussed in Cicon \& Sofrin. ${ }^{9}$ In comparing the results between the two exit conditions, the 2-rake results show that the incident $+x$ direction mode power level remained about constant while the flange $-x$ direction mode power level increased by $6 \mathrm{~dB}$ over that of the lip exit condition. The final transmitted mode power remained constant between the two exit conditions. Previously, 1-rake analysis results would be used to estimate the level of radiated noise. The Table 3 results show that the fixed rake mode power levels are close (within $0.3 \mathrm{~dB}$ ) to the transmitted mode power levels with the lip in place at the duct exit showing that in this case, the 1-rake results give a reasonable estimate of the transmitted sound power. However, with the rake at a different location, the mode power level estimate would have been $1.4 \mathrm{~dB}$ higher than the transmitted power level. With the flange exit condition, the potential for error in estimating transmitted mode power levels with one rake gets larger. 


\begin{tabular}{|c|c|c|c|c|c|c|c|}
\hline Exit Type & Mode & $+x$ & \multicolumn{1}{|c|}{$-x$} & Movable & Fixed & Trans. & $\Delta^{(*)}$ \\
\hline Lip & $(2,0)$ & 116.1 & 99.6 & $115.7-117.4$ & 116.3 & 116.0 & 0.3 \\
Flange & $(2,0)$ & 116.4 & 106.0 & $114.1-118.6$ & 118.1 & 116.0 & 2.1 \\
\hline
\end{tabular}

(*) Fixed rake power level - Transmitted power level

Table 3. Propagating mode power levels in decibels comparing 1-rake and 2-rake analyses of ANCF in-duct measured data with either the lip or flange exit conditions. $480 \mathrm{~Hz}$.

Another set of data was obtained with the sound sources set to generate a circumferential mode at $m=2$ with a frequency of $960 \mathrm{~Hz}$. These conditions allow 3 propagating modes, $(2,0),(2,1)$, and $(2,2)$. The eigenvalues for these modes are shown in Table 1. Rotating rake data were collected for 1 fixed rake and 1 movable rake in the same manner as the $480 \mathrm{~Hz}$ example discussed above. The results are summarized in Table 4 for the computed mode power levels both from the 1-rake analysis for each rake separately and from the 2-rake analysis to obtain $+x$ and $-x$ direction propagating mode power levels. Again, the fixed rake mode power levels are all higher than the transmitted mode power levels with the difference at the lip exit condition being smaller, as expected, than the difference at the flange exit condition.

\begin{tabular}{|c|c|c|r|r|c|c|c|}
\hline Exit Type & Mode & $+x$ & \multicolumn{1}{c|}{$-x$} & \multicolumn{1}{c|}{ Movable } & Fixed & Trans. & $\Delta^{(*)}$ \\
\hline Lip & $(2,0)$ & 103.9 & 89.4 & $101.2-103.3$ & 105.3 & 103.8 & 1.5 \\
& $(2,1)$ & 106.8 & 93.4 & $105.2-107.0$ & 108.0 & 106.6 & 1.4 \\
& $(2,2)$ & 110.4 & 83.1 & $109.5-110.6$ & 110.7 & 110.4 & 0.3 \\
\hline \multirow{2}{*}{ Flange } & $(2,0)$ & 103.4 & 97.6 & $97.6-105.2$ & 106.9 & 102.1 & 4.8 \\
& $(2,1)$ & 107.8 & 98.8 & $104.3-109.6$ & 110.4 & 107.2 & 3.2 \\
& $(2,2)$ & 111.0 & 101.3 & $110.0-113.4$ & 112.3 & 110.4 & 1.9 \\
\hline
\end{tabular}

(*) Fixed rake power level - Transmitted power level

Table 4. Propagating mode power levels in decibels comparing 1-rake and 2-rake analyses of ANCF in-duct measured data with either the lip or flange exit conditions. $960 \mathrm{~Hz}$.

\section{III.C. Measurement and Computational Results Comparison}

The NASA Glenn Research Center Broadband Aeroacoustic Stator Simulation (BASS) code was used for numerical calculations that modeled the ANCF duct with no flow and artificial noise sources. The BASS code is a high-order, high-accuracy unsteady computational aeroacoustics code which uses explicit fourthorder time marching schemes combined with high order spatial differencing schemes to accurately solve the unsteady nonlinear Euler equations. ${ }^{13}$ It uses structured multiblock grids for topological flexibility, is written in standard Fortran 2003, and uses parallelization. For this work, the BASS code was run using the HALE-RK67 time marching scheme ${ }^{21}$ the Tam \& $\mathrm{Webb}^{22}$ 7-point DRP scheme for the spatial differencing, and the Giles ${ }^{23}$ nonreflecting boundary conditions at the boundaries of the computational domain.

The computational domain begins outside the ANCF inlet (shown in Figure 8) and continues into the duct, terminating at the acoustic driver location. The incoming acoustic modes are imposed at this boundary. The nonreflecting boundary condition allows outgoing waves to exit the computational domain, which is located outside of the duct lip shown in the figure, with minimal reflection. The grid, generated using the GridPro/az3000 grid generator, ${ }^{24}$ had a minimum of 10 grid points per wavelength of the highest-frequency acoustic modes.

The BASS code computed results for the two frequency cases, $480 \mathrm{~Hz}$ and $960 \mathrm{~Hz}$, at the $m=2$ circumferential mode that were measured in the ANCF duct with the lip exit condition. The code could not simulate the sources, hence mode shapes and amplitudes were input for the propagating modes in each case. Given the low levels of the sound and the no flow conditions, the code should have linear behavior and the modes propagate without interaction between modes. The mode incoming to the lip exit should reflect off the change in duct condition at that point and send a reflected mode propagating in the opposite direction. The 


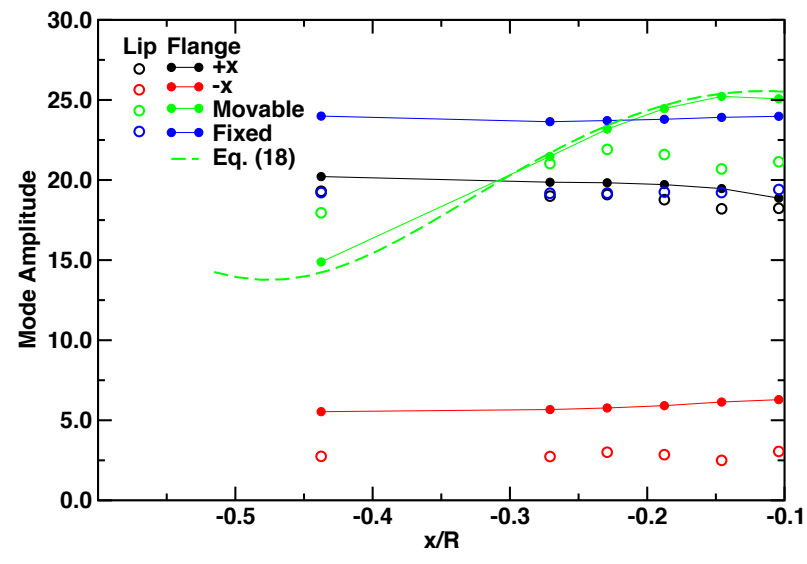

Figure 10. Comparison of 1-rake and 2-rake analyses for mode amplitude using ANCF measured data with a lip mounted exit (Figure 8) and a no-lip or flange only exit. $480 \mathrm{~Hz}$, mode $(2,0)$.

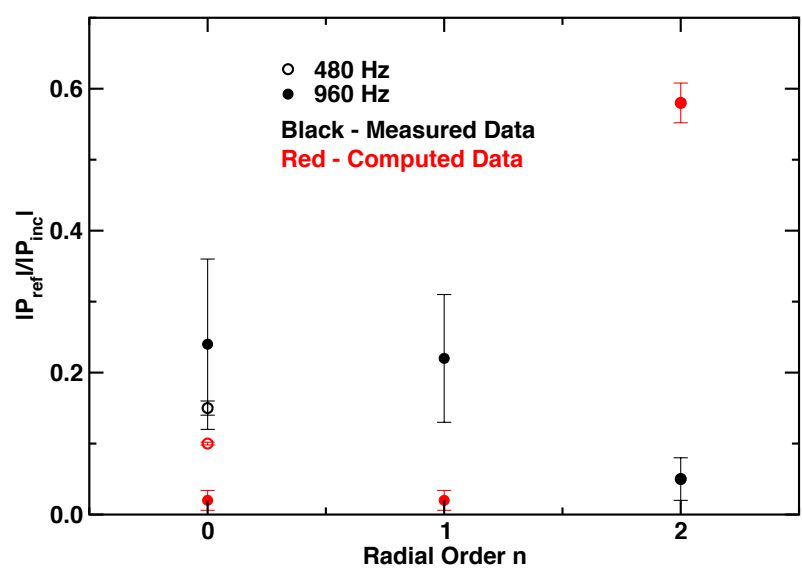

Figure 11. Comparison of results of 2-rake analysis of measured data and computed data in terms of a reflection coefficient, the ratio of reflected to incident mode amplitudes. $m=2$

data can then be collected in the uniform region of the duct in a manner that simulates a rake measurement. The BASS code does not compute the same acoustic field in the duct compared to the measured ANCF duct data since the sources are not the same. However, the physics of mode reflection should be present in the computed results such that the ratio of the reflected mode amplitude to the incident mode amplitude should be the same between computed and measured results regardless of the actual incident amplitude. Results for this ratio or reflection coefficient from both computed and measured data are plotted in Figure 11 for the 1 mode at $480 \mathrm{~Hz}$ and the 3 modes at $960 \mathrm{~Hz}$. The closet comparison between measured and computed values occurs at $480 \mathrm{~Hz}$. At $960 \mathrm{~Hz}$, the computations show very little reflections except at the $n=2$ mode. From Table 1, this mode is shown to be near cutoff where, as Meyer ${ }^{10}$ and Nallasamy et al. ${ }^{11}$ have shown in computed results, the reflection coefficient can increase near cutoff. The reflection coefficient from measured data does not show this behavior. However, these results are preliminary and further investigation of the numerical and the measured results are required.

\section{Concluding Remarks}

The rotating rake mode measurement data analysis process has been extended from the analysis of data from 1 rake to include the data simultaneously collected from a co-rotating second rake. Since measurements at one rake location will not provide sufficient data to determine the direction of propagating modes, a second rake measurement axially separated from the first rake is minimally necessary. The analysis of the data from each rake is initially the same, providing total circumferential mode amplitudes at each microphone location identified with the harmonic number of the blade-passing frequency and the circumferential mode number. As the modes propagate within the duct, the amplitudes and phases change. By taking the data from 2 microphone rakes simultaneously, these changes are captured in the total circumferential mode amplitudes. The two sets of total circumferential mode amplitudes are considered to be the sum of radial basis functions half of which may be viewed as propagating in one direction and the other half propagating in the other direction. The mode amplitudes at both measurement locations are the same. Hence, using a least-squares fit to the total circumferential mode amplitudes from both locations, the mode amplitudes that apply to modes propagating in both directions are obtained. With a rearrangement of the equations fitting the radial basis functions to the total circumferential mode amplitudes, evanescent modes are properly included in the fit. These modes have some amplitude at one measurement location but have little or no amplitude at the other location in the direction that damping occurs.

Testing of the data analysis technique for 2 rotating rakes used data from simulation and in-duct measurements. The simulated data recreated the conditions in a duct with incident and reflected modes from a boundary. We showed that the 1-rake measurement and data analysis resulted in mode amplitudes that were the amplitudes of the standing wave in the duct. It was only when any reflected mode amplitude was small that the 1-rake analysis provided the mode amplitude for the propagating mode in one direction. Using 2-rake analysis, the mode amplitudes were obtained for both modes propagating in the two directions. The 
simulation also showed that if there was significant evanescent mode amplitude at a measurement location that was not included in the fitting process, the fitting process would put erroneous amounts of energy into the propagating modes. Thus, evanescent modes need to be properly included in the fit, when necessary, to obtain the correct mode amplitudes for the propagating modes. The analysis of the measured data verified the simulation for the measurement of 1-rake data in a standing wave and 2-rake data separating the mode amplitudes for modes propagating in both directions. Mode power levels were also computed from the results of 1-rake and 2-rake analyses. These results showed the difference between the mode power levels computed from 1-rake analysis data and the transmitted mode power levels from 2-rake analysis data.

\section{Appendix - Rotating Rake Data Analysis for Two Rakes}

Consider the signal

$$
p(x, \theta, r, t)=\Re\left\{\sum_{s} \sum_{m=-M}^{M} C_{m}^{s}(x, r) e^{-j 2 \pi s B \Omega t} e^{j m \theta}\right\}
$$

where the frequency $s B \Omega$ is related to a rotating fan with $\Omega$, the shaft speed in revolutions per second, $B$, the number of blades, and, $s$, the harmonic number $s=1,2, \ldots$. The signal is sampled synchronously with the shaft speed and ensembled averaged over a period $T=K \Delta t$. This reduces the uncorrelated broadband noise in favor of the tonal content of the signal. The circumferential mode index $m$ ranges over a finite number of modes denoted by the general value $M$.

Each microphone in the two rakes is generating a signal of the type shown in equation (19). The first rake, Rake $B$, is located at

$$
\begin{aligned}
x_{B} & =\text { reference axial location } \\
\theta_{B} & =\text { reference angle } \\
r_{i} & =\text { signals at different } \operatorname{radii} r_{i}, i=1,2, \ldots, N_{B}
\end{aligned}
$$

The second rake, Rake $\mathrm{A}$, is located at

$$
\begin{aligned}
& x_{A}=\text { axial location } \\
& \theta_{A}=\theta_{B}+\phi \text { offset azimuthally } \\
& r_{i^{\prime}}^{\prime}=\text { signals at different radii } r_{i^{\prime}}^{\prime}, i^{\prime}=1,2, \ldots, N_{A}
\end{aligned}
$$

The number and radial locations of the microphones are not assumed to be the same on the two rakes.

The rakes are rotating according to $\theta_{B}=2 \pi \Gamma t$. For Rake A, equation (19) becomes

$$
\begin{aligned}
p\left(x_{A}, \theta_{A}, r_{i^{\prime}}^{\prime}, t\right) & =\Re\left\{\sum_{s} \sum_{m=-M}^{M} C_{m}^{s}\left(x_{A}, r_{i^{\prime}}^{\prime}\right) e^{-j 2 \pi s B \Omega t} e^{j m \theta_{A}}\right\} \\
& =\Re\left\{\sum_{s} \sum_{m=-M}^{M} C_{m}^{s}\left(x_{A}, r_{i^{\prime}}^{\prime}\right) e^{-j 2 \pi s B \Omega t} e^{j m\left(\theta_{B}+\phi\right)}\right\} \\
& =\Re\left\{\sum_{s} \sum_{m=-M}^{M} C_{m}^{s}\left(x_{A}, r_{i^{\prime}}^{\prime}\right) e^{j m \phi} e^{-j 2 \pi(s B \Omega-m \Gamma) t}\right\}
\end{aligned}
$$

The equation for Rake $\mathrm{B}$ is similar with $\phi=0$. Taking the discrete Fourier transform for all the rake microphone signals represented by equation (20), we obtain for any spectral component of the signals:

$$
\begin{aligned}
\text { Rake B: } \quad \hat{P}_{m}^{s}\left(x_{B}, 0, r_{i}, \ell\right) & =\frac{1}{2} C_{m}^{s}\left(x_{B}, r_{i}\right) h(n-\ell)+\frac{1}{2} C_{m}^{s *}\left(x_{B}, r_{i}\right) h(K-n-\ell) \\
\text { Rake A: } \quad \hat{P}_{m}^{s}\left(x_{A}, \phi, r_{i^{\prime}}^{\prime}, \ell\right) & =\frac{1}{2} C_{m}^{s}\left(x_{A}, r_{i^{\prime}}^{\prime}\right) e^{j m \phi} h(n-\ell)+\frac{1}{2} C_{m}^{s *}\left(x_{A}, r_{i^{\prime}}^{\prime}\right) e^{-j m \phi} h(K-n-\ell) \\
\ell & =0,1,2, \ldots, K-1
\end{aligned}
$$

where $h$ is a function representing spectral leakage if the tones are not centered in the frequency bins. That is, if

$$
\ell=n=n_{r}\left(\frac{s B \Omega}{\Gamma}-m\right)
$$


where $n_{r}$ is the number of rake revolutions in the time history $T$ and the right side is an integer, then $h \rightarrow 1$ and there is no spectral leakage. Equation (21) shows that the spectrum contains families of spikes about each harmonic $s$ having the amplitudes of the $\pm m$ circumferential modes. These amplitudes can be simply extracted using

$$
\begin{array}{ll}
\text { Rake B: } \quad C_{m}^{s}\left(x_{B}, r_{i}\right) & =2 \hat{P}_{m}^{s}\left(x_{B}, 0, r_{i}, \ell\right) \\
\text { Rake A: } \quad C_{m}^{s}\left(x_{A}, r_{i^{\prime}}^{\prime}\right) & =2 \hat{P}_{m}^{s}\left(x_{A}, \phi, r_{i^{\prime}}^{\prime}, \ell\right) e^{-j m \phi}
\end{array}
$$

In current practice, the signals from both rakes are processed identically such that $C_{m}^{s}=2 \hat{P}_{m}^{s}$ for Rake A and the rotation by $e^{-j m \phi}$ is applied during the solution for the radial modes as shown in equation (15).

\section{References}

${ }^{1}$ Cicon, D. E., Sofrin, T. G., and Matthews, D. C., "Investigation of a Continuously Traversing Microphone System for Mode Measurement," NASA CR-168040, PWA-5846-26, November 1982.

${ }^{2}$ Hall, D. G., Heidelberg, L., and Konno, K., "Acoustic Mode Measurements in the Inlet of a Model Turbofan Using a Continuously Rotating Rake: Data Collection/Analysis Technique," AIAA Paper No. 93-0599, 1993.

${ }^{3}$ Sutliff, D. L., "Rotating Rake Turbofan Duct Mode Measurement System," NASA TM-2005-213828, October 2005.

${ }^{4}$ Sutliff, D. L., "Rotating Rake Mode Measurements Over Passive Treatment in a Ducted Fan," NASA TM-2006-214493, December 2006.

${ }^{5}$ Sutliff, D. L., "Turbofan Duct Mode Measurements Using a Continuously Rotating Microphone Rake," Int. J. of Aeroacoustics, Vol. 6, No. 2, 2007, pp. 147-170.

${ }^{6}$ Dahl, M. D. and Sutliff, D. L., "Numerical Technique for Analyzing Rotating Rake Mode Measurements in a Duct With Passive Treatment and Shear Flow," AIAA Paper No. 2007-3679, 2007.

${ }^{7}$ Envia, E., Tweedt, D. L., Woodward, R. P., Elliott, D. M., Fite, E. B., Hughes, C. E., Podboy, G. G., and Sutliff, D. L., "Fan Noise Prediction," Assessment of NASA's Aircraft Noise Prediction Capability, edited by M. D. Dahl, NASA TP-2012-215653, chap. 5, 2012.

${ }^{8}$ Heidelberg, L. J. and Hall, D. G., "Inlet Acoustic Mode Measurement Using a Continuously Rotating Rake," J. Aircraft, Vol. 32, No. 4, July 1995, pp. 761-767.

${ }^{9}$ Cicon, D. E. and Sofrin, T. G., "Method for Extracting Forward Acoustic Wave Components from Rotating Microphone Measurements in the Inlets of Turbofan Engines," NASA CR-195457, April 1995.

${ }^{10}$ Meyer, H. D., "Effect of Inlet Reflections on Fan Noise Radiation," AIAA J., Vol. 34, No. 9, 1996, pp. $1771-1777$.

${ }^{11}$ Nallasamy, M., Sutliff, D. L., and Heidelberg, L. J., "Propagation of Spinning Acoustic Modes in Turbofan Exhaust Ducts," J. Prop. Power, Vol. 16, No. 5, September 2000, pp. 736-743.

${ }^{12}$ Zorumski, W. E., "Generalized Radiation Impedances and Reflection Coefficients of Circular and Annular Ducts," J. Acoust. Soc. Am., Vol. 54, No. 6, 1973, pp. 1667-1673.

${ }^{13}$ Hixon, R., Nallasamy, M., and Sawyer, S., "Parallization Strategy for an Explicit Computational Aeroacoustics Code," AIAA Paper No. 2002-2583, 2002.

14 Åbom, M., "Modal Decomposition in Ducts Based on Transfer Function Measurements Between Microphone Pairs," J. Sound Vib., Vol. 135, No. 1, 1989, pp. 95-114.

${ }^{15}$ Akoum, M. and Ville, J.-M., "Measurement of the Reflection Matrix of a Discontinuity in a Duct," J. Acoust. Soc. Am., Vol. 103, 1998, pp. 2463-2468.

${ }^{16}$ Schultz, T., Cattafesta, L. N., and Sheplak, M., "Modal Decomposition Method for Acoustic Impedance Testing in Square Ducts," J. Acoust. Soc. Am., Vol. 120, No. 6, 2006, pp. 3750-3758.

${ }^{17}$ Rademaker, E. R., "Experimental Validation of a Lined-Duct Acoustics Model Including Flow," ASME Paper No. 90WA/NCA-2, Presented at the ASME Winter Annual Meeting, Dallas, TX, Nov. 1990, 1990.

${ }^{18}$ Ovenden, N. C. and Rienstra, S. W., "Mode-Matching Strategies in Slowly Varying Engine Ducts," AIAA J., Vol. 42, No. 9, September 2004, pp. 1832-1840.

${ }^{19}$ Lawson, C. L. and Hanson, R. J., Solving Least Squares Problems, Prentice-Hall, Englewood Cliffs, NJ, 1974.

${ }^{20}$ Loew, R. A., Lauer, J. T., McAllister, J., and Sutliff, D. L., "The Advanced Noise Control Fan," AIAA Paper No. 2006-3150, 2006.

${ }^{21}$ Allampali, V., Hixon, R., Nallasamy, M., and Sawyer, S., "High-Accuracy Large-Step Explicit Rung-Kutta (HALE-RK) Schemes for Computational Aeroacoustics," J. Comp. Physics, Vol. 228, No. 10, 2009, pp. 3837-3850.

${ }^{22}$ Tam, C. K. W. and Webb, J. C., "Dispersion-Relation-Preserving Finite Difference Schemes for Computational Acoustics," J. Comp. Physics, Vol. 107, No. 2, 1993, pp. 262-281.

${ }^{23}$ Giles, M. B., "Nonreflecting Boundary Conditions for Euler Equation Calculations," AIAA J., Vol. 28, 1990, pp. 20502058.

${ }^{24}$ GridPro/az3000, Program Development Company, White Plains, NY, 1993-2010. 


\begin{tabular}{|c|c|c|}
\hline \multicolumn{2}{|c|}{ REPORT DOCUMENTATION PAGE } & $\begin{array}{l}\text { Form Approved } \\
\text { OMB No. 0704-0188 }\end{array}$ \\
\hline \multicolumn{3}{|c|}{ 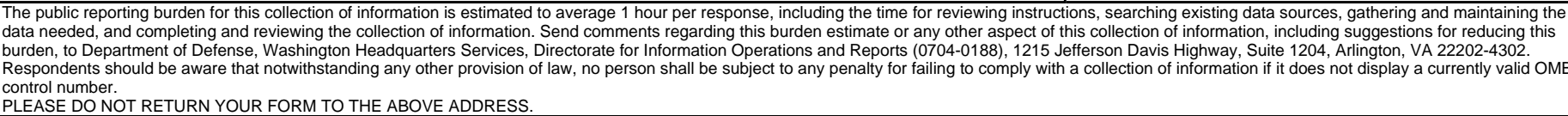 } \\
\hline $\begin{array}{l}\text { 1. REPORT DATE (DD-MM-YYYY) } \\
01-06-2013\end{array}$ & $\begin{array}{l}\text { 2. REPORT TYPE } \\
\text { Technical Memorandum }\end{array}$ & 3. DATES COVERED (From - To) \\
\hline \multirow{3}{*}{\multicolumn{2}{|c|}{$\begin{array}{l}\text { 4. TITLE AND SUBTITLE } \\
\text { Further Development of Rotating Rake Mode Measurement Data A }\end{array}$}} & 5a. CONTRACT NUMBER \\
\hline & & 5b. GRANT NUMBER \\
\hline & & 5c. PROGRAM ELEMENT NUMBER \\
\hline \multirow{3}{*}{\multicolumn{2}{|c|}{$\begin{array}{l}\text { 6. AUTHOR(S) } \\
\text { Dahl, Milo, D.; Hixon, Ray; Sutliff, Daniel, L. }\end{array}$}} & 5d. PROJECT NUMBER \\
\hline & & 5e. TASK NUMBER \\
\hline & & $\begin{array}{l}\text { 5f. WORK UNIT NUMBER } \\
\text { WBS 473452.02.03.07.06.01.03 }\end{array}$ \\
\hline \multicolumn{2}{|c|}{$\begin{array}{l}\text { 7. PERFORMING ORGANIZATION NAME(S) AND ADDRESS(ES) } \\
\text { National Aeronautics and Space Administration } \\
\text { John H. Glenn Research Center at Lewis Field } \\
\text { Cleveland, Ohio 44135-3191 }\end{array}$} & $\begin{array}{l}\text { 8. PERFORMING ORGANIZATION } \\
\text { REPORT NUMBER } \\
\text { E-18701 }\end{array}$ \\
\hline \multirow{2}{*}{\multicolumn{2}{|c|}{$\begin{array}{l}\text { 9. SPONSORING/MONITORING AGENCY NAME(S) AND ADDRESS(ES) } \\
\text { National Aeronautics and Space Administration } \\
\text { Washington, DC 20546-0001 }\end{array}$}} & $\begin{array}{l}\text { 10. SPONSORING/MONITOR'S } \\
\text { ACRONYM(S) } \\
\text { NASA }\end{array}$ \\
\hline & & $\begin{array}{l}\text { 11. SPONSORING/MONITORING } \\
\text { REPORT NUMBER } \\
\text { NASA/TM-2013-217890 }\end{array}$ \\
\hline \multicolumn{3}{|c|}{$\begin{array}{l}\text { 12. DISTRIBUTION/AVAILABILITY STATEMENT } \\
\text { Unclassified-Unlimited } \\
\text { Subject Category: } 71 \\
\text { Available electronically at http://www.sti.nasa.gov } \\
\text { This publication is available from the NASA Center for AeroSpace Information, 443-757-5802 }\end{array}$} \\
\hline
\end{tabular}

\section{SUPPLEMENTARY NOTES}

\section{ABSTRACT}

The Rotating Rake mode measurement system was designed to measure acoustic duct modes generated by a fan stage. After analysis of the measured data, the mode amplitudes and phases were quantified. For low-speed fans within axisymmetric ducts, mode power levels computed from rotating rake measured data would agree with the far-field power levels on a tone by tone basis. However, this agreement required that the sound from the noise sources within the duct propagated outward from the duct exit without reflection at the exit and previous studies suggested conditions could exist where significant reflections could occur. To directly measure the modes propagating in both directions within a duct, a second rake was mounted to the rotating system with an offset in both the axial and the azimuthal directions. The rotating rake data analysis technique was extended to include the data measured by the second rake. The analysis resulted in a set of circumferential mode levels at each of the two rake microphone locations. Radial basis functions were then least-squares fit to this data to obtain the radial mode amplitudes for the modes propagating in both directions within the duct. The fit equations were also modified to allow evanescent mode amplitudes to be computed. This extension of the rotating rake data analysis technique was tested using simulated data, numerical code produced data, and preliminary in-duct measured data.

\section{SUBJECT TERMS}

Turbofan; Duct modes; Aeroacoustics; Measuring techniques; Spectral methods; Accuracy

\begin{tabular}{|c|c|c|c|c|c|}
\hline \multicolumn{3}{|c|}{ 16. SECURITY CLASSIFICATION OF: } & \multirow{2}{*}{$\begin{array}{l}\text { 17. LIMITATION OF } \\
\text { ABSTRACT } \\
\text { UU }\end{array}$} & \multirow{2}{*}{$\begin{array}{l}\text { 18. NUMBER } \\
\text { OF } \\
\text { PAGES } \\
22\end{array}$} & \multirow{2}{*}{$\begin{array}{l}\text { 19a. NAME OF RESPONSIBLE PERSON } \\
\text { STI Help Desk (email:help@sti.nasa.gov) } \\
\text { 19b. TELEPHONE NUMBER (include area code) } \\
\text { 443-757-5802 }\end{array}$} \\
\hline $\begin{array}{l}\text { a. REPORT } \\
\text { U }\end{array}$ & $\begin{array}{l}\text { b. ABSTRACT } \\
U\end{array}$ & $\begin{array}{l}\text { c. THIS } \\
\text { PAGE } \\
\text { U }\end{array}$ & & & \\
\hline
\end{tabular}



